\title{
SENSOR APPLICATIONS IN ANALYSIS OF DRUGS AND FORMULATIONS
}

\section{AKIFULHAQUE ${ }^{1}$, G. R. SHIVACHARAN ${ }^{1}$, M. D. PARVEEN ${ }^{2}$, D. K. SHANTHI PRIYA ${ }^{1}$, TEJA KUMAR REDDY KONATHAM ${ }^{3}$, NARMADA VALLAKEERTHI ${ }^{3}$}

${ }^{1}$ Department of Pharmaceutical Analysis, Anurag University, Venkatapur, Ghatkesar, Hyderabad, Telangana, India. ${ }^{2}$ Department of

Pharmaceutics, Max Institute of Pharmaceutical Sciences, Velugumatla, Khammam, Telangana, India. ${ }^{3}$ Department of Pharmacy, University College of Technology, Osmania University, Hyderabad, Telangana, India. E-mail: akif963@gmail.com

Received: 17 February 2021, Revised and Accepted: 01 October 2021

\begin{abstract}
Several sensors, biosensors, and actuators are designed and mounted to analyze biomedical nutraceuticals, food, and nutraceutical products in this particular issue. Some applications concern classical subjects such as eubacteria determination in agricultural products, flashing material in foods such as the ethyl group's chemicals, and fruit juices' inhibitor properties. In contrast, the different applications are more revolutionary, such as safety research, the manufacture of artificial human senses (electronic nose or tongue), or t Ligands are often characterized by nano biosensors, utilizing biomaterials that involve specific aptamers, antibodies, enzymes, polymers, and sensory receptors. The square measurement of several modal sensing elements, integrated with nanomaterials, increases sensitivity such as nano biosensors and increases nano biosensor productivity. For the nano biosensor with increased efficiency, modality sensing components have been incorporated in this case. The square measurement of the elastic (ME) magnetic machine biosensors was used to classify infectious agents by a magnet coil in contemporary juice or milk and to develop direct detection of infectious agents on food scanning coils.
\end{abstract}

Keywords: Biosensor devices, Nutraceuticals, Clostridium, Food packaging, Bio electrodes, Nano biosensor, Magneto elastic, Pathogen.

(C) 2021 The Authors. Published by Innovare Academic Sciences Pvt Ltd. This is an open access article under the CC BY license (http://creativecommons.org/ licenses/by/4.0/) DOI: http://dx.doi.org/10.22159/ajpcr.2021v14i11.41134. Journal homepage: https://innovareacademics.in/journals/index.php/ajpcr

\section{INTRODUCTION}

The growth of sensors and biosensors in the last quantity is essential for two reasons; one from a technological point of origin. The other from a psychological one A biosensor primarily includes two parts, a physical, electrical system, and a biological recognition component. Salmonellaspecific bacteriophage E2 (5 $108 \mathrm{CFU} / \mathrm{mL}$ ) was hand-picked since this part of bio identification. The sensors were also submerging for one hour within the bacterium suspension to realize uniform physical adsorption on the surfaces.

Since the amorphous magnetic alloy is magnetic and has a physical resonance with other frequencies, it displays a time-changing magnetic flux. As the biosensor mass intensifies, its resonant frequency decreases with the interaction of the disease. Compared to the initial group of the biosensor, the mass increase is minimal. Liang et al. and Guntupalli et al. give the change inside the resonant frequency.

Enzyme-based biosensors area unit for bioprocess management applicable within the pharmaceutical industry facilitated the emergence, in real-time, of analytes of desired interest, such as aldohexose, glutamate, amino acid, and lactate.

\section{PLACEMENT OF BIOSENSORS}

Square biosensors for those sectors, for example, biotechnology, biomedicine, food technology, and agriculture. In vitro biosensor study square measures in a tube, micro titer plate, culture platform, or outside the living animal. In vivo, although a biosensor may be a system planted within the body. In vivo biosensor sterilization should perhaps be primarily confined to implants to prevent a primary inflammatory response.

\section{APPLICATIONS}

Biosensors area unit is wide applicable within the health research. A number of the critical applications area unit mentioned during this review.

\section{BIOSENSORS-PERSPECTIVE}

The biosensors have been routinely implemented in many fields. The fields encompass biomedicine, tissue engineering, food processing, and the environment. Within the production of organic-specific chips, "Biosensors are relevant to the preservation of three-D integrity and cell culture configurations" [1]. Biosensors are used within food preservation activities throughout the fermentation cycle and may even be accustomed to monitoring nephrotoxic metals in foods, to pesticide detection in juices and wine [2-5].

\section{TYPES OF BIOSENSORS}

\section{Resonant biosensor}

The biosensor predominantly uses the vibrant frequency concept that is proportional to organic chemistry reaction. The immobilized material on the sensing membrane is associated with the sample.

\section{Thermal biosensors}

Biosensor equipment, semiconductor accelerator, and electrical equipment are supplied. This biosensor comprises the immobilized membrane, including its accelerator. In general, the enzyme semiconductor device is configured to use the thermal biosensor to detect pesticides [6].

\section{Electrochemical biosensor}

Therefore, the electrochemical sensor involves the generation or absorption of ions and electrons. Set and transform this electrical parameter into the assigned parameter [7]. A number of electrochemical sensors fabricated using hybrid nanocomposite materials have been applied for electrochemical sensing of electroactive compounds of interest such as drugs due to their novel and multi-functional properties $[8,9]$. Electrochemical sensors measure the changes of electrical parameters in relation to modifications of chemical properties. Basically, a chemical reaction produces an electrical signal at the electrode by a modification in current, potential or conductivity that is detected by transducer [10]. These biosensors can be used for detect enzymes, nucleic acids, antibodies, whole cells, and receptors, being the enzymes the most common analyte [11]. 


\begin{tabular}{|c|c|c|}
\hline Transduction & Biosensor type & Applications \\
\hline \multirow[t]{3}{*}{ Electrochemical } & Acetylcholinesterase (AChE) inhibition biosensors & Pesticidal study \\
\hline & Hba1c biosensor & Determining glycated hemoglobin \\
\hline & Uric acid biosensors & $\begin{array}{l}\text { Diagnosis of various clinical abnormalities or illness (e.g., } \\
\text { diagnosis of cardiovascular disease) }\end{array}$ \\
\hline \multirow[t]{3}{*}{ Optical } & Polyacrylamide based hydrogel biosensors & Immobilization of biomolecules \\
\hline & Silicon biosensor & For bio sensing, bio imaging, and in cancer therapy \\
\hline & Micro fabricated biosensor & In novel drug delivery (e.g., in optical corrections) \\
\hline Electrochemical or optical & Nanomaterials biosensors & For diagnosis and in drug delivery \\
\hline
\end{tabular}

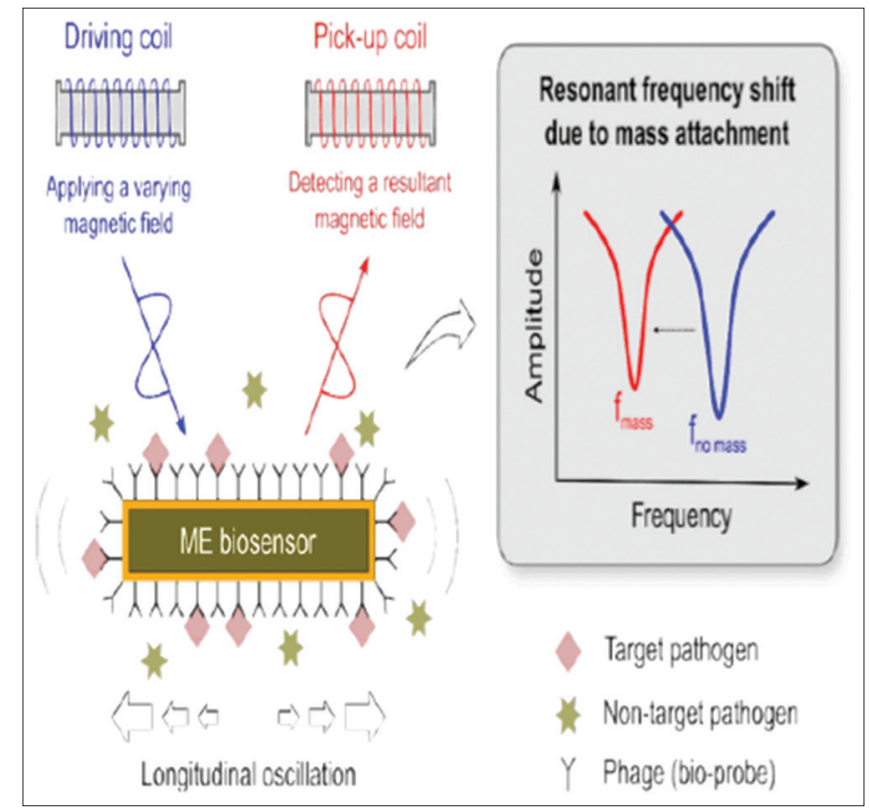

Fig. 1: Detection principle of ME biosensor

\section{Glucose biosensor}

Glucose biosensor consists of the glucose (GOD) enzyme immobilized inside the dialysis membrane, incorporated in the oxygen electrodes' interior. The crucial notion of the global biosensor is based on the fact that the immobilized GOx catalyzes $\beta$-D glucose oxidation by the use of gluconic acid and peroxide-producing molecular oxygen [1]. GOx needs a redox cofactor - Flavin adenine dinucleotide in an attempt to serve as a catalyst (FAD). FAD operates since the electron acceptor is provisional and is reduced to FADH2.

Glucose + GOx - FAD + GL - FADH2 Glucolactone + GOx

The cofactor is regenerated by reacting with oxygen, and hydrogen peroxides are produced.

$$
\text { GOx - FADH2 + } 02-\text { FAD + H2 O2 - GOx }
$$

\section{DNA biosensor}

The sensory components are enzymes, antibodies, DNA, microorganisms; chemistry, optics, or acoustics are the electrical unit an electrical signal system the main biosensor. The current output is linearly proportional to the electroactive product's concentration that is subsequently proportional to the non-electroactive accelerator substrate [12].

\section{Microbial biosensors}

Scientists build biological victimization engineering microbial biosensors (e.g., arsenic biosensors) [13]

Nanomaterials as biosensors: Nanostructure-aided biosensors in this area are now the main themes in the medical field. New types of nanomaterial bio-sensors are shown to improve the ability of tiny fictitious deployable devices. [14]

\section{Ozone biosensors}

Ozone biosensors are essential due to the highly harmful UV gas filters. The chemical biosensor technique consists of 2 parts: A selective gas sorbent content, that is, eugenol, and a gas amperometric biosensor built in a transmission cell. Adjust the flow to the covalent bond radical of eugenol, becomes immobilized into a hydrophobic C-18 reactor, and creates gas collected [15].

\section{THE BIOSENSOR IN FOOD SAFETY ANALYSIS}

The above relates specifically to food safety research. It is practiced explicitly in health care units (POCs) wherever a standard chromatography-mass qualitative analysis combined technique is obstructed, as it requires a long time and trained hands to induce results $[16,17]$.

Like fruit juices, square examines a broad supply of various biologically active compounds such as vitamins C, tocopherols, carotenoids, and polyphenols. Square measurements have created antioxidant sources and are thought to lead to upset, cancer, and degeneration. Their consumption has been extremely rapid in the past few years. Fruit juices such as pomegranate, apple, peach, and various fruits combined. As a consequence, the interest in style and emerging analytical approaches arise worldwide. The Elbehery paper attempts to offer a brand new answer to this question [18]. Ghasemi-varnamkhasti et al. worked on the monitoring of ageing of beer using enzymatic biosensors, based on cobalt phthalocyanine. These biosensors evinced a good capability to monitor the ageing of beer during storage [19].

\section{GLUCOSE BIOSENSOR DEVELOPMENT USING ETLINGERA THEIR EXTRACT}

Diabetes mellitus (DM) can be a cluster of high glucose macromolecule upset.

DM complication, which caused 1.5 million deaths in 2012, causes coronary insufficiency, blindness, nephropathy, lower limb amputation, and stroke [20]. By different biosensor applications, Aldohexose Biosensor was commonly available on the market. Increasing the aldohexose biosensor remains a fascinating subject for performance analysis [21], price reduction [22], or the atmospheric advancement of technology within analysis studies. Within detection concepts or the instrumentation, the event of biosensors can be performed.

\section{GLUCOSE BIOSENSOR INDICATOR STUDY USING ETLINGERA THEIR EXTRACT}

Aldohexose resolution and aldohexose enzyme accelerator were used to evaluate the floral extract's efficacy as an aldohexose biosensor indicator. The sequence of aldohexose resolution samples is a $\mathrm{pH} 7.0$ phosphate tampon. A resolution of $5 \mathrm{ml}$ of aldohexose was prepared in the tubing, another ten accelerators incubate in temperature for a quarter-hour.

\section{APPLICATIONS}

1. Biosensors square measure applicable in varied fields, with miniaturization and fewer value, has exaggerated the device's analytical capabilities. 
2. Biosensors analysis is booming around the world, and also, the space of applications varies from medical to agriculture.

3. Biosensors are applicable in detecting the food-borne infective agent, ensuring food safety associated as an indicator of product satisfactoriness.

4. Biosensors have emerged as a sizeable applicable tool in the food trade to spot target specificity, negatron integration, and stability.

5. DNA testing of the cow and the identification of organisms within the milk and biosensors square measure will not check for sterilization and preservation. The inherent specificity, sensitivity, and adaptability make the ideal candidate for use throughout the food industry $[23,24]$.

\section{CONCLUSION}

Several new developed techniques and technology evolution; biosensors have improved and square measure applicable in many fields. Thanks to this, the detection of dangerous diseases will be achieved. So biosensors square measure essential to human health and also the system also.

Etlin Gera elatior flower ethanol-HCl extract might be used as an associate degree indicator of aldohexose detection for a simple chemistry approach of early aldohexose detection, victimization quantitative analysis, strategies utilization of aldohexose enzyme protein. The projected methodology showed an honest dimensionality (0 - a hundred millimeter, R2 $=0.9965)$ and high sensitivity $(y=-0.0005 x+0.4724)$. The Etlin Gera elatior flower extract showed high stability against $\mathrm{pH}$ scale, redactor, heating treatment, and stability throughout storage at $4^{\circ} \mathrm{C}$.

\section{CONFLICT OF INTERESTS}

There is no conflict of interest for this review article

\section{AUTHOR FUNDING}

There is no funding for this review article

\section{REFERENCES}

1. Mehrotra P. Biosensors and their applications-a review. J Oral Biol Craniofac Res 2016;6:153-9.

2. Thakur MS, Ragavan KV. Biosensors in food processing. J Food Sci Technol 2013;50:625-41

3. Wang J. Electrochemical glucose biosensors. Chem Rev 2008; 108:814-25.

4. Ivanov I, Younusov RR, Evtugyn GA, Arduini F, Moscone D, Palleschi G. Cholinesterase sensors based on screen-printed electrodes for detection of organophosphorus and carbamic pesticides. Anal Bioanal Chem 2003;377:624-31.

5. Suprun E, Evtugyn G, Budnikov H, Ricci F, Moscone D, Palleschi G. Acetylcholinesterase sensor based on screen-printed carbon electrode modified with Prussian blue. Anal Bioanal Chem 2005;383:597-604.

6. Nguyen HH, Lee SH, Lee UJ, Fermin CD, Kim M. Immobilized enzymes in biosensor applications. Materials (Basel) 2019;12:121 .

7. Weibel MK, Bright HJ. The glucose oxidase mechanism. Interpretation of the $\mathrm{pH}$ dependence. J Biol Chem 2008;8:1400-58.

8. Goud KY, Satyanarayana M, Hayat A, Gobi KV, Marty JL. Nanomaterialbased electrochemical sensors in pharmaceutical applications editor. In: Grumezescu AM, editor. Nanoparticles in Pharmacotherapy. Ch. 7. New York: William Andrew Publishing; 2019. p. 195-216.

9. Kumar S, Bukkitgar SD, Singh S, Singh V, Reddy KR, Shetti NP, et al. Electrochemical sensors and biosensors based on graphene functionalized with metal oxide nanostructures for healthcare applications. Chem Select 2019;4:5322-37.

10. Veloso A, Cheng X, Kerman K. 1-electrochemical biosensors for medical applications. In: Higson S, editors. Biosensors for Medical Applications. Illinois, United States: Woodhead Publishing; 2012. p. $3-40$.

11. Grieshaber D, MacKenzie R, Voeroes J, Reimhult E. Electrochemical Biosensors-Sensor principles and architectures. Sensors 2008;8:1400-58.

12. D'Souza SF, Jha SK, Kumar J. Environmental biosensors. IANCS bulletin. Environ Biotech 2005;4:54-59.

13. Chen J, Rosen BP. Biosensors for inorganic and organic arsenicals. Biosensors (Basel) 2014;4:494-512.

14. Yun YH, Eteshola E, Bhattacharya A, Dong Z, Shim JS, Conforti L, et al. Tiny medicine: Nanomaterial-based biosensors. Sensors (Basel) 2009;9:9275-99.

15. Stergiou DV, Prodromidis MI, Efstathiou CE. On the possibility of a pHmetric determination of ozone. Electrochem Commun 2009;12:262-5.

16. Choi JR, Yong KW, Choi JY, Cowie AC. Emerging point-of-care technologies for food safety analysis. Sensors 2019;19:817.

17. Elbehery NH, Amr AE, Kamel AH, Elsayed EA, Hassan SS. Novel potentiometric 2, 6-dichlorophenolindo-phenolate (DCPIP) membranebased sensors: Assessment of their input in the determination of total phenolics and ascorbic acid in beverages. Sensors 2019;19:2058.

18. Wild S, Roglic G, Green A, Sicree R, King H. Global prevalence of diabetes: Estimates for the year 2000 and projections for 2030. Diabetes Care 2004;27:1047-53.

19. Ghasemi-Varnamkhasti M. Rodriguez-Mendez ML, Mohtasebi SS, Apetrei C, Lozano J, Ahmadi H, et al. Monitoring the aging of beers using a bioelectronic tongue. Food Control 2012;25:216-24.

20. Fantoni A, Numnuam A, Kanatharana P, Limbut W, Thammakhet-Buranachai C, Thavarungkul P. A highly stable oxygen- independent glucose biosensor based on a chitosan-albumin cryogel incorporated with carbon nanotubes ferrocene. Sensors Actuators B Chem 2013;185:725-34.

21. Fantoni A, Anggraeni MD, Dwiasi DW. Simple colorimetric glucose biosensor using chitosan cryogel supporting material. AIP Conf Proc 2016;1746:020029.

22. Fantoni A, Dwiasi DW, Hermawan D. Alginate cryogel based glucose biosensor. IOP Conf Ser 2016;107:012010.

23. Murugaboopathi G, Parthasarathy V, Chellaram C, Anand TP, Vinurajkumar S. Applications of biosensors in food industry. Biosci Biotechnol Res Asia 2013;10:707-11.

24. Sharma H, Agarwal M, Goswami M, Sharma A, Roy SK, Rai R, et al. Biosensors: Tool for food borne pathogen detection. Vet World 2013;6:968-73. 